\title{
Preliminary report: genetic variation in the human stromelysin promoter is associated with progression of coronary atherosclerosis
}

\author{
Shu Ye, Gerald F Watts, Sundhiya Mandalia, Steve E Humphries, Adriano M Henney
}

\begin{abstract}
Stromelysin is a member of the family of metalloproteinases that degrade extracellular matrix. In situ hybridisation and histopathological studies suggest that stromelysin activity may be important in the connective tissue remodelling processes associated with atherogenesis and plaque rupture. Single strand conformation polymorphism analysis identified a common polymorphism in the stromelysin gene promoter located 1171 bp upstream from the start of transcription in which one allele has a run of six adenosines (6A) and another has five adenosines (5A). 72 men with coronary heart disease, were genotyped. They were participants in the St Thomas' Atherosclerosis Regression Study who were randomised to receive usual care (UC), dietary intervention (D), or diet plus cholestyramine (DC), with angiography at baseline and at 39 months. In these patients the frequency of the $5 \mathrm{~A}$ allele was $0.49(95 \% \mathrm{CI}$ from 0.41 to 0.57$)$ and was not significantly different from that in a sample of 354 healthy UK men. In the UC group, patients who were homozygous for the $6 \mathrm{~A}$ allele showed greater progression of angiographic disease than those with other genotypes: the minimum absolute width of coronary segments decreased by 0.04 (SEM 0.10) $\mathrm{mm}$ for $5 A 5 A, 0.20(0.07) \mathrm{mm}$ for $5 A 6 A$, and $0.67(0.19) \mathrm{mm}$ for 6A6A $(P<0.01)$. The findings were similar but slightly less significant for the change in mean absolute width of coronary segments $(P<$ $0.05)$. No significant associations were seen in patients in the D or DC groups. In data pooled from the three treatment groups, the 6A6A genotype was significantly associated with greater progression of coronary atherosclerosis than other genotypes in patients with baseline percentage diameter stenosis $<20 \%(P<$ 0.05 ), but not in those with baseline percentage diameter stenosis $\geqslant 20 \%$.

These results provide the first evidence of a link between genetic variation in stromelysin and progression of coronary atherosclerosis and support the hypothesis that connective tissue remodelling mediated by metalloproteinases contributes to the pathogenesis of atherosclerosis.
\end{abstract}

(Br Heart f 1995;73:209-215)
Keywords: stromelysin; progression of coronary artery disease; polymorphism

Coronary thrombosis may result in significant reduction in myocardial perfusion and the development of clinical ischaemic syndromes, or it may become organised and incorporated into the diseased artery, thus contributing to the progression of atherosclerosis. ${ }^{1-4}$ The commonest cause of coronary thrombosis is tearing (fissuring) of atherosclerotic plaque caps, which exposes collagen, tissue factors, and lipids to the circulation, leading to platelet activation and initiation of the coagulation cascade. ${ }^{1-5}$ It has been suggested that weakening of the connective tissue in the intimal layer, perhaps mediated by enzymes secreted by foam cells, is responsible for the increased circumferential stress that leads to plaque fissuring. ${ }^{56}$ Using in situ hybridisation and immunocytochemistry, we have previously shown that stromelysin, a member of the family of metalloproteinases (MMPs) that degrade extracellular matrix, was expressed in atherosclerotic plaques. Extensive stromelysin expression was found in accumulated foam cells that were of macrophage origin. ${ }^{\text {? }}$ Stromelysin mRNA transcripts and proteins were also localised to isolated smooth muscle cells in the plaque cap, intima, and adventitia. These observations suggest that stromelysin may be involved in connective tissue remodelling associated with rupture and the development of atherosclerotic plaques. ${ }^{7}$

The MMPs are a group of enzymes including collagenases, gelatinases, and stromelysins, that can degrade all extracellular matrix macromolecules and which are involved in physiological and pathological events associated with connective tissue resorption. ${ }^{89}$ Stromelysin has the widest substrate specificity in the MMP family and can degrade many of the constituents of the extracellular matrix within atherosclerotic plaques. The principal substrate is proteoglycan, but this enzyme can also degrade types II, IV, and IX collagen; laminin; fibronectin; and gelatin, and activate other members in the MMPs family such as the collagenases. ${ }^{8-10}$

Stromelysin expression is regulated primarily at the level of transcription. The promoter of the gene responds to different regulators including platelet-derived growth factor-beta $(\mathrm{PDGF}-\beta)$ and interleukin-1 (IL-1). ${ }^{11-14}$ Sequence variation in this region might disrupt the finely balanced control of matrix remodelling and result in predisposition to more rapid progression of disease. In the 
present study, we used single strand conformation polymorphism analysis to screen the stromelysin promoter for sequence variation and identified a common polymorphism located $1171 \mathrm{bp}$ upstream from the start of transcription. We genotyped 72 patients with coronary artery disease who participated in the St Thomas' Atherosclerosis Regression Study (STARS), ${ }^{15}$ a randomised, controlled, end-point-blinded trial of atherosclerosis regression with different lipid lowering interventions. We analysed the relation between the polymorphism and progression of coronary atherosclerosis determined by quantitative image analysis of coronary angiograms.

\section{Patients and methods}

SAMPLES, STUDY DESIGN AND CORONARY ANGIOGRAPHY

The clinical and demographic characteristics of the patients, as well as the study design, techniques for coronary angiography, and other clinical measurements in the $\mathrm{St}$ Thomas' Atherosclerosis Regression Study (STARS) are described in detail elsewhere. ${ }^{15}$ Briefly, 90 men (aged less than 66 years, with a plasma cholesterol concentration above 6.0 $\mathrm{mmol} / \mathrm{l}$ but not exceeding $10 \mathrm{mmol} / \mathrm{l}$ and not treated with lipid-lowering drugs) referred for coronary angiography to investigate angina pectoris or other findings suggestive of coronary artery disease (CAD) were recruited and 74 of them completed the study. The patients had coronary angiography and plasma lipids and lipoproteins measured before being randomly assigned to one of three treatment groups: a lipid lowering diet (D), diet plus cholestyramine (DC), or usual care only (U). There were no statistically significant differences in baseline angiographic data and plasma lipid and lipoprotein concentrations between the treatment groups. Coronary angiography was repeated about three years after randomisation (mean (SD) 39 (3.5) months). Paired measurements were made by a computerised method ${ }^{15}$ on 489 segments: a mean (SD) of $6.4 \quad(2 \cdot 0)$ segments was analysed per patient. The study end points were the overall change (per patient) in mean and minimum absolute width of coronary seg-

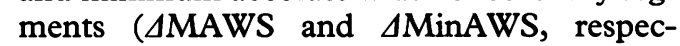
tively).

The frequency of genetic variants was also assessed in 354 healthy men from Surrey, England. The details of this study were reported elsewhere. ${ }^{16}$

DNA ISOLATION, POLYMERASE CHAIN REACTION (PCR)

Genomic DNA was extracted from blood nucleated cells by a salting out procedure. ${ }^{17}$ PCR was carried out in a total volume of $50 \mu \mathrm{l}$ containing $0.5 \mu \mathrm{g}$ genomic DNA; $200 \mathrm{ng}$ of each oligonucleotide primer; $200 \mu \mathrm{M}$ of dATP, dCTP, dDTP, dTTP; $50 \mathrm{mM} \mathrm{KCl}$; $10 \mathrm{mM}$ Tris- $\mathrm{HCl}$ (pH 8.3); $2 \mathrm{mM} \mathrm{MgCl}_{2}$; $0.001 \%(\mathrm{w} / \mathrm{v})$ gelatin; $0.05 \%$ WI detergent (Life Technologies, USA); and 1 U Taq polymerase. The solution was overlaid with $50 \mu \mathrm{l}$



Figure 1 Diagram of the human stromelysin promoter. The $5 A / 6$ A polymorphism is located 1171 bp upstream from the start of transcription. SL2, SL5, SL9, and SLINT1 are PCR primers (see text); GRE and $A P-1$ indicate, respectively, the positions of the glucocorticoid responsive elements and the Activator Protein-1 binding sequence.

liquid paraffin and was incubated for three minutes at $93^{\circ} \mathrm{C}$, followed by 30 cycles of one minute at $93^{\circ} \mathrm{C}$, one minute at $55^{\circ} \mathrm{C}$, and one minute at $72^{\circ} \mathrm{C}$. The following oligonucleotide primers were used in these experiments; the exact positions within the promoter are given in brackets, using numbering from Quinones et $a l,{ }^{18}$ with approximate locations shown schematically in fig 1: Forward primer: (SL5, - 1259 to - 1240) 5' -GATTACAGACATGGGTCACG-3' Reverse primer: (SL2, -845 to -826$)$ 5' -TAAAATATAGCAAACTTTTG-3'.

\section{SINGLE STRAND CONFORMATION}

POLYMORPHISM (SSCP) ANALYSIS

Radioactive PCR was carried out by including an addition of $0.3 \mu \mathrm{Ci}\left[a^{32} \mathrm{P}\right] \mathrm{dCTP}$ per reaction. Amplified DNA fragments larger than the optimal size for SSCP were digested with appropriate restriction endonucleases in a solution containing $20 \mu \mathrm{l} \mathrm{PCR}$ product, $3 \mu \mathrm{g}$ bovine serum albumin, $1 \times$ digestion buffer, and 5-10 U enzyme at the recommended temperatures overnight. The digests, mixed with an equal volume of stop solution ( $95 \%$ formamide, $20 \mathrm{mM}$ EDTA, $0.05 \%$ bromophenol blue and $0.05 \%$ xylene cynol), were boiled for 3 minutes and loaded onto a $4.5 \%$ non-denaturing polyacrylamide gel (acrylamide:bisacrylamide $=49: 1$ ) with or without $10 \%$ glycerol. Electrophoresis was performed at room temperature for 12 to 16 hours or at $4^{\circ} \mathrm{C}$ for three to six hours. The gel was dried and autoradiographed for 1-3 days.

\section{NUCLEOTIDE SEQUENCE ANALYSIS}

PCR products were purified from unincorporated nucleotides and primers using Dynabeads M-280 streptavidin from Dynal AS and sequenced according to the dideoxynucleotide chain termination method using $\left[a-{ }^{35} \mathrm{~S}\right]$ dATP, modified $\mathrm{T}_{7}$ DNA polymerase (Sequenase, United States Biochemical). Both DNA strands were sequenced using the PCR primers described above.

ALLELE SPECIFIC OLIGONUCLEOTIDE (ASO) HYBRIDISATION

$20 \mu$ of PCR products were separated on a $1.2 \%$ agarose gel and denatured in $0.5 \mathrm{M}$ 
$\mathrm{NaOH}$, and $1.5 \mathrm{M} \mathrm{NaCl}$ for 40 minutes. Denatured DNAs were transferred onto two Hybond-N + nylon membranes by placing a membrane on each side of the agarose gel and blotting overnight. Two probes hybridising specifically to the $5 \mathrm{~A}$ or $6 \mathrm{~A}$ alleles $\left(5^{\prime}-\right.$ GGGAAAAAACCATG-3' and 5'-ACATGGTTTTTCCC- $3^{\prime}$ ) were $5^{\prime}$ end labelled with $\left[\gamma-{ }^{32} \mathrm{P}\right]$ ATP. The membranes were prehybridised in $5 \times \operatorname{SSPE}(0.15 \mathrm{M} \mathrm{NaCl}, 0.01 \mathrm{M}$ $\mathrm{NaH}_{2} \mathrm{PO}_{4}$, and 0.001 M EDTA, pH 7.4), $5 \times$ Denhardts $\quad(0.1 \%$ Ficoll $400,0.1 \%$ polyvinylpyrolidone, and $0 \cdot 1 \%$ bovine serum albumin), and $0.5 \%$ sodium dodecyl sulphate (SDS) at $36^{\circ} \mathrm{C}$ for 10 minutes. Each of the two membranes was hybridised separately to one of the probes in a hybridisation solution containing $5 \times$ SSPE, $5 \times$ Denhardts, $0.5 \%$ sodium dodecyl sulphate (SDS), and $1 \times 10^{6}$ $\mathrm{cpm} / \mathrm{ml}$ probe at $36^{\circ} \mathrm{C}$ for one hour. The membranes were washed together in $5 \times$ SSC, $0.1 \% \mathrm{SDS}$ at $40^{\circ} \mathrm{C}$ for five minutes. Autoradiograms were prepared by exposing films to membranes at $-70^{\circ} \mathrm{C}$ for $12-24$ hours with intensifying screens. Samples of known genotype were used as markers and run alongside the samples being analysed. All genotyping was assessed independently by two individuals who were blinded to the treatment grouping of the samples. Technical difficulties with PCR amplification prevented the genotypes of two patients from being obtained, one each from treatment groups D and DC.

\section{STATISTICAL ANALYSIS}

Allele frequency was estimated by the gene counting method. $\chi^{2}$ analysis was used to test deviations of genotype distribution from Hardy-Weinberg equilibrium and to determine whether there was any significant difference in allele or genotype frequencies between patient and control groups. To examine association between genotypes and $\triangle \mathrm{MAWS}$ or $\triangle$ MinAWS, a one way analysis of variance (ANOVA) and an unpaired Student's $t$ test were carried out in all patients as a whole and in the three treatment groups considered separately. Analyses were also performed on the whole patient group stratified above and below the medians for baseline percentage diameter stenosis (20\%) and for in-trial plasma low density lipoprotein (LDL) cholesterol concentrations $(4.2 \mathrm{mmol} / \mathrm{l})$. Multiple linear regression analysis was used to adjust $\triangle M A W S$ and $\triangle M$ MinAWS for age, weight, blood pressure, and smoking status. All statistical analyses except the $\chi^{2}$ tests were carried out using the Minitab statistical package. In this study $P<0.05$ was taken to be statistical significance.
1
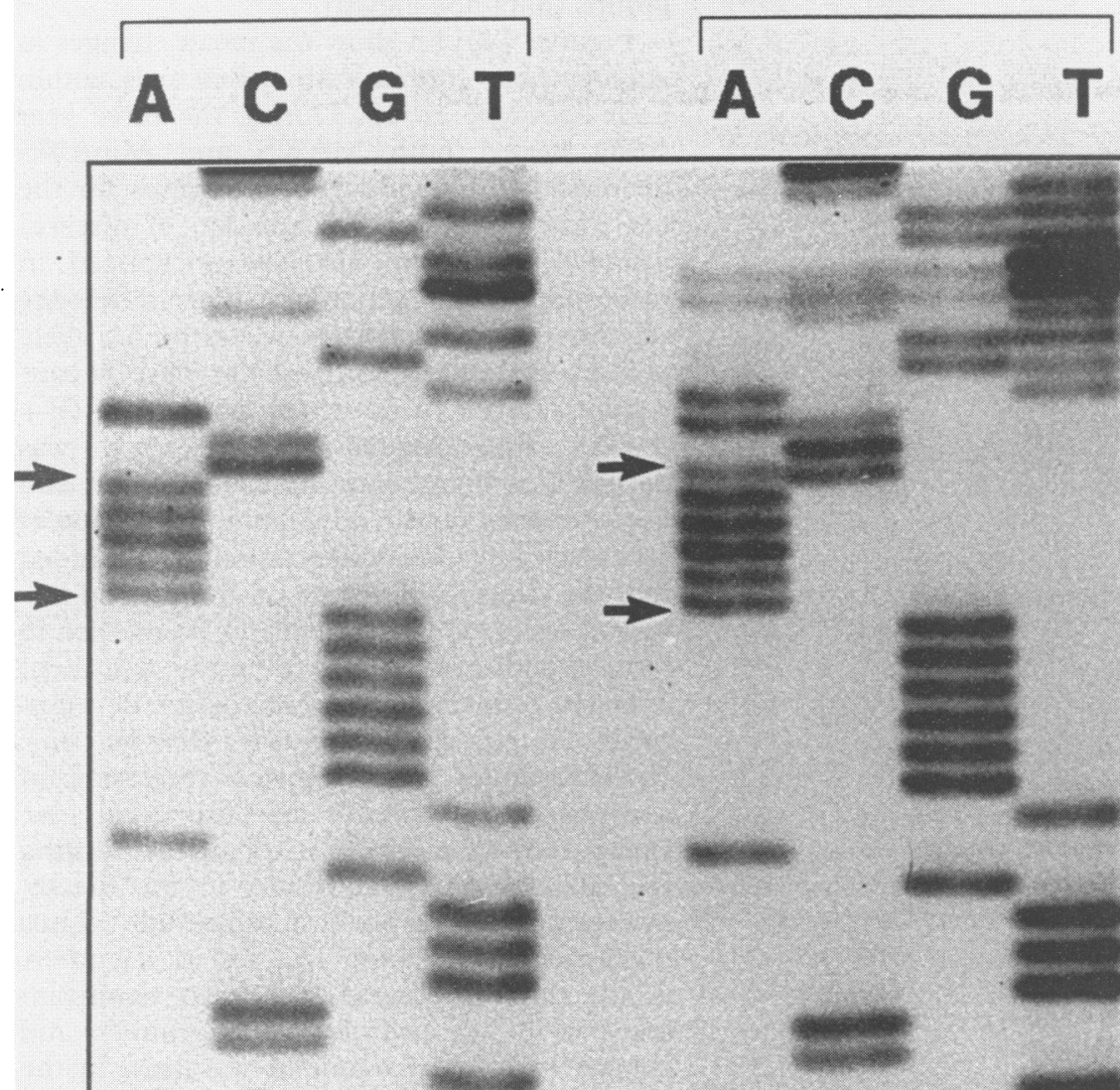

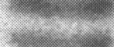
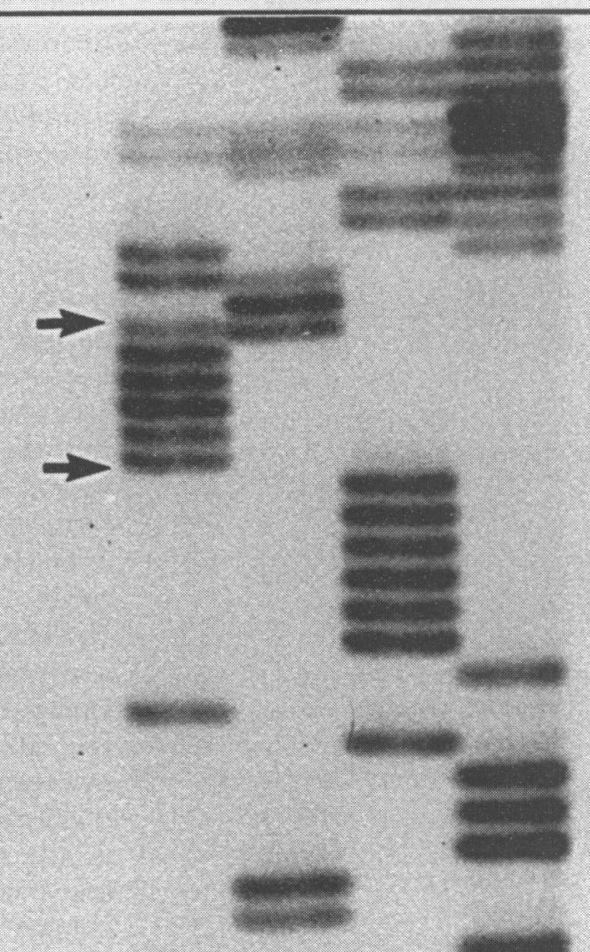

20



Figure 2 Direct sequencing autoradiograph from individuals homozygous for $5 A$ (left), heterozygote (middle), and homozygous for $6 A$ (right). 


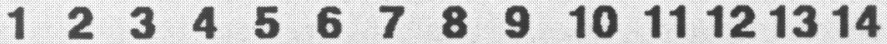

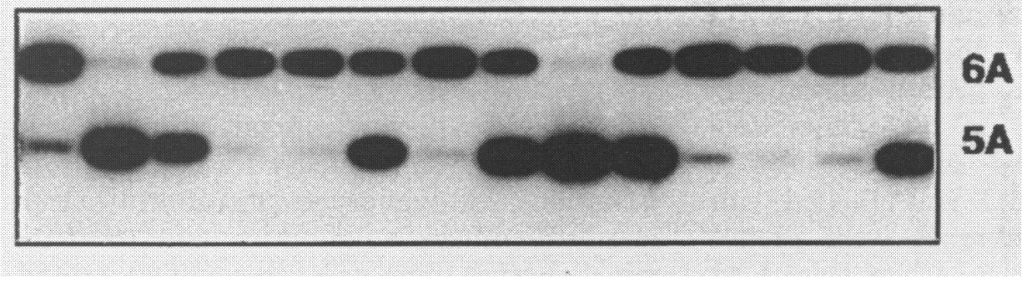

Figure 3 Autoradiograph of allele specific oligonucleotide hybridisation. Inferred genotypes are, respectively, $6 A 6 A$ in lanes $1,4,5,7,11,12$, and 13; $5 A 5 A$ in lanes 2 and $9 ;$ and $5 A 6 A$ in lanes $3,6,8,10$ and 14 .

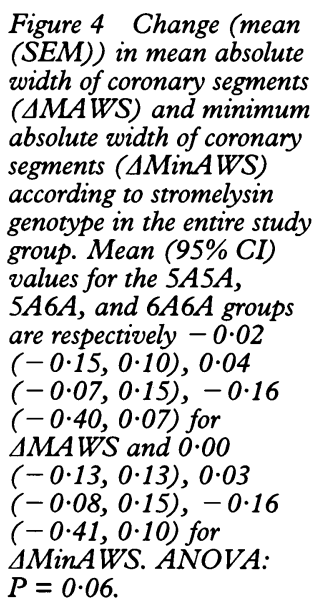
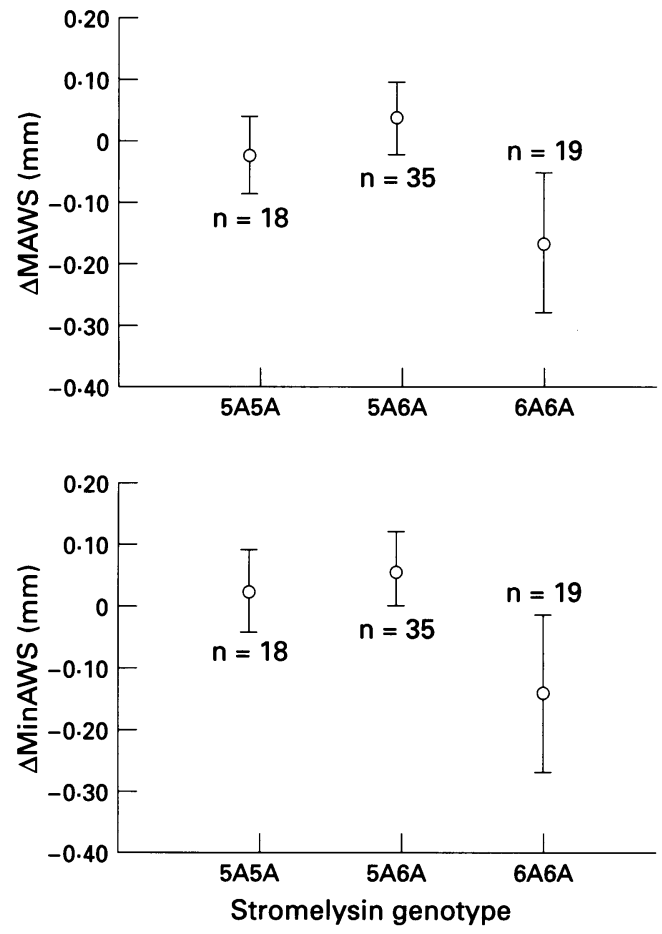

Figure 5 Change (mean (SEM)) in mean absolute width of coronary segments ( $\triangle M A W S$ ) and minimum absolute width of coronary segments ( $\triangle M$ MinAWS) according to stromelysin genotype in the usual care group only. Mean (95\% CI) values for the $5 A 5 A$ $5 A 6 A$, and $6 A 6 A$ groups are respectively -0.05 $(-0.31,0 \cdot 21),-0 \cdot 18$ $(-0.35,-0.02),-0.53$ $(-1.00,-0.05)$ for $\triangle M A W S$ and -0.04 $(-0 \cdot 29,0 \cdot 20),-0 \cdot 20$ $(-0.36,-0.04),-0.67$ $(-1 \cdot 26,-0 \cdot 08)$ for $\triangle M$ MinS ANOVA: $P$ $=0.02$ for $\triangle M A W S$ and $P=0.003$ for $\triangle M$ Min $A W S$.

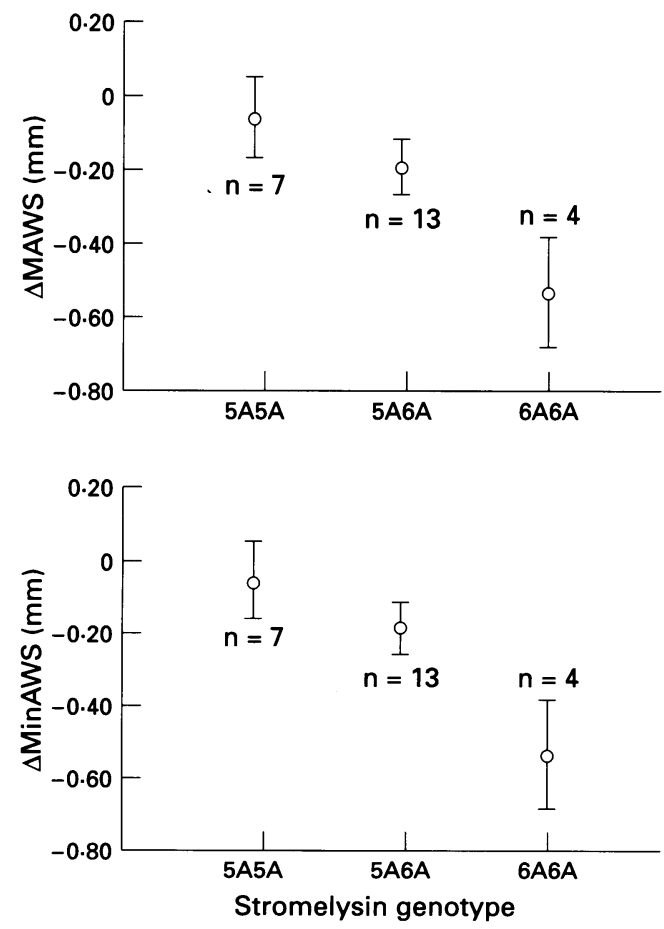

\section{Results}

Figure 1 is a schematic representation of the stromelysin gene promoter. In the present study, overlapping PCR-SSCP analyses were used to screen for sequence variation covering the entire $1306 \mathrm{bp}$ of the promoter region, as well as the first exon which encodes the signal peptide of the protease. The sequence from -1259 to -826 was amplified using PCR primers SL5 and SL2, and cut into two fragments (181 bp and $258 \mathrm{bp}$ respectively) by $E c o R I$ digestion before non-denaturing polyacrylamide gel electrophoresis. Variations in electrophoretic mobility were seen in the 181 bp fragment in 29 out of 40 individuals. PCR and direct sequencing showed that this was due to variation at position -1171 where an adenosine had been deleted from a run of six adenosines when compared with published sequences (fig 2). ${ }^{18}$ The allele that has five adenosines was designated $5 \mathrm{~A}$ and the one that contains six adenosines was designated 6A. Analysis of the remainder of this region revealed no other frequent sequence variants.

The 72 patients who completed the STARS study and 354 healthy controls from the United Kingdom were genotyped for the $5 \mathrm{~A} / 6 \mathrm{~A}$ polymorphism by ASO hybridisation (fig 3c). The frequency of the $5 \mathrm{~A}$ allele was $0.49(95 \%$ CI from 0.41 to 0.57$)$ in patients and was not significantly different from that in controls: 0.52 ( $95 \%$ CI from 0.48 to 0.56 ). Genotype distributions in both patients and controls were close to and not significantly different from the Hardy-Weinberg prediction, and were similar for the three treatment groups (data not shown).

Figures 4 and 5 show the mean changes in angiographic coronary atherosclerosis within each genotype group. During the three year study period both MAWS and MinAWS decreased in individuals homozygous for the $6 \mathrm{~A}$ allele (indicating progression of disease) whereas they were virtually unchanged in those with other genotypes. This difference suggests an association between the $6 \mathrm{~A}$ allele and disease progression and was close to conventional levels of statistical significance $(P=$ 0.065). The original STARS study was designed to investigate the effect of diet and lipid lowering on the progression/regression of atherosclerosis. It could reasonably be argued that the effect of genotype on the natural history of lesion progression might be masked in those groups randomised to receive treatment aimed at reducing or reversing lesion development. As reported previously, the diet plus cholestyramine group showed regression of coronary artery disease and the usual care group showed progression of disease during the trial period, with results in the dietary intervention group being intermediate. ${ }^{15}$ Thus the genetic association was tested separately in the three treatment groups. A significant association between the polymorphism and change in luminal diameter was seen in the UC group (fig 5) where the decrease in MinAWS in patients homozygous for the $6 \mathrm{~A}$ allele was $4 \cdot 8$-fold greater than that in those with other genotypes $(P=0.003)$. The 
findings were similar in measures of the change in MAWS, with a decrease that was $3 \cdot 7$-fold greater in individuals with the genotype $6 \mathrm{~A} 6 \mathrm{~A}$ than in those with other genotypes $(P=0.02)$. No significant associations were seen in patients in the $\mathrm{D}$ or DC treatment groups (data not shown).

It has been observed that lesions causing less severe stenosis are liable to more rapid progression than those that cause more severe stenosis. ${ }^{19-21}$ In patients with less severe coronary disease at baseline (percentage diameter stenosis less than the median value of $20 \%$ ), there was a significant association between genotype and lesion progression, which was maintained after adjustment for covariates such as age, body weight, smoking, and blood pressure. Individuals with the genotype 6A6A showed a mean decrease of MAWS and MinAWS by $0.27 \mathrm{~mm}$ and $0.31 \mathrm{~mm}$ respectively during the study period (that is, progression of disease), whereas those with other genotypes did not show significant changes ( $\mathrm{P}=0.048$ and 0.046 for $\triangle \mathrm{MAWS}$ and $\triangle$ MinAWS respectively, data not shown). In patients with percentage diameter stenosis $\geqslant 20 \%$, a trend toward lower mean values of $\triangle \mathrm{MAWS}$ and $\triangle \mathrm{MinAWS}$ in those with genotype 6A6A was also seen, but did not reach statistical significance.

Based on the previous observation in this sample that changes in coronary lumen diameter were significantly correlated with plasma LDL cholesterol concentrations during the trial period, ${ }^{15}$ association analysis was carried out separately in patients stratified according to LDL cholesterol (that is, above and below the median value of $4.2 \mathrm{mmol} / \mathrm{l}$ ). In patients with a high plasma LDL cholesterol, the reduction of adjusted MinAWS in those who were homozygous for the $6 \mathrm{~A}$ allele was fourfold greater than that in those with one or more copies of the 5A allele $(P=0.045$, data not shown). There was no association between genotype and disease progression in those in whom LDL cholesterol was $\leqslant 4 \cdot 2$ $\mathrm{mmol} / \mathrm{l}$.

\section{Discussion}

In this study we found an association between a common polymorphism in the stromelysin promoter and progression of coronary atherosclerotic disease in patients participating in STARS. Overall, the 6A6A genotype was associated with a decrease in measures of MAWS and MinAWS, indicating progression of disease, which was significant in those with the least severe disease at baseline (stenosis $\leqslant 20 \%$ ) and those with highest on-trial LDL. Although the same trend was also seen in patients with baseline stenosis $>20 \%$ and those with lower on trial LDL, the difference between the genotype 6A6 A and other genotypes was not significant.

These data suggest that this polymorphism, or another sequence change that is in linkage disequilibrium with it, may affect the transcription of the stromelysin gene. Expression of the stromelysin gene and its natural inhibitor (TIMP) is regulated by various agents including cytokines, growth factors, tumour promoters, and oncogene products. ${ }^{131422-26}$ The induction of stromelysin expression can be subsequently suppressed by transforming growth factor-betal (TGF- $\beta 1$ ), ${ }^{27}$ dexamethasone, and retinoic acid. ${ }^{14} 1828$ It is known that the promoter region of the stromelysin gene contains multiple DNA responsive elements, ${ }^{11} 121829$ and the activator protein-1 (AP-1) binding site, located between positions -63 and -70 , has been found to mediate the IL-1 or phorbol 12myristate 13 -acetate induction, ${ }^{29}$ whereas three sequences $(-1300$ to $-1286,-871$ to -857 , and -150 to -136 ) that share strong homology with the glucocorticoid-responsive consensus element have been implicated in the dexamethasone suppression. ${ }^{18}$ The DNA element responsible for induction of stromelysin by PDGF-B has been localised to the region between -1279 and -1240 by deletion analysis: this is within $100 \mathrm{bp}$ of the $5 \mathrm{~A} / 6 \mathrm{~A}$ polymorphism. ${ }^{12}$ Thus sequence variation in this region might affect response to certain stimuli and disrupt the normal regulatory process through altered stromelysin concentrations in local connective tissue. In addition, because both MMPs and their inhibitors are coordinately expressed in response to several cytokine and growth factor stimuli, ${ }^{8}$ sequence changes affecting the transcription of enzyme and not the inhibitor may disrupt the normal balance expected for coordinated expression. We hypothesise that the $5 \mathrm{~A} / 6 \mathrm{~A}$ polymorphism, or another sequence change closely linked to it, affects the binding of nuclear proteins involved in the regulation of stromelysin gene expression, as has been shown for a similar polymorphism in the promoter of the plasminogen activator inhibitor type-1 gene. ${ }^{30}$ We propose that, as connective tissue resorption is the result of a carefully controlled balance between MMP enzymes and their inhibitors, variation in levels of transcription in one and not the other could create a potential imbalance and result in genotypespecific variation in matrix degradation. Thus imbalances favouring increased degradation may result in matrix weakening in the plaque cap, increasing the risk of fissuring; conversely, reduced degradation would favour the deposition of connective tissue in the lesion, adding to its bulk and contributing to its growth.

Over the past few years, several studies have shown that coronary atherosclerotic lesions causing less severe stenosis as determined by angiography are more liable to rapid progression to severe stenosis. ${ }^{19-21}$ Studying the angiographic evolution of coronary artery morphology in patients with unstable angina, Ambrose et al found that more than two thirds of the lesions that progressed showed mild stenosis $(<50 \%)$ on the first angiography. ${ }^{20}$ This was supported by a study of Little et al which showed that the artery that subsequently occluded had less than $50 \%$ luminal diameter narrowing on the initial angiography in two thirds of patients and less than $70 \%$ in 
almost all patients. ${ }^{21}$ The observations in the present study accord with these findings: coronary lesions progressed more rapidly in the subgroup with baseline stenosis $\leqslant 20 \%$, and in this subgroup, those with genotype 6A6A were liable to even more rapid progression. In contrast, in the subgroup with stenosis $>20 \%$ at baseline, atherosclerotic lesions progressed relatively more slowly and the difference between genotype classes was therefore less pronounced.

The association between the $5 \mathrm{~A} / 6 \mathrm{~A}$ polymorphism and change in MinAWS was observed most strongly in patients with a plasma LDL cholesterol concentration greater than $4.2 \mathrm{mmol} / \mathrm{l}$, and not in patients with lower concentrations. It has been shown in other studies that progression of atherosclerosis is positively correlated with LDL-cholesterol concentrations and regression with HDL cholesterol concentrations. ${ }^{15}{ }^{31}$ High plasma concentrations of LDL cholesterol result in uptake of LDL particles in the artery wall and subsequent oxidation in the intima. ${ }^{19}$ Products of oxidised LDL may alter gene expression of intimal cells such as PDGF, a regulatory factor for stromelysin expression. Rouis et al showed that cultured macrophages loaded with acetyl-LDL secreted an undefined, elastin-degrading metalloproteinase, the activity of which is positively correlated with the cholesterol content of the cells. ${ }^{32}$ This is supported by data from our group which suggest that acetyl LDL stimulates macrophages to express stromelysin and TIMP-1 (Rennick and Henney, unpublished observations). In the present study, the association between the 6A6A genotype and change in MinAWS was seen most strongly in patients with a higher LDL cholesterol concentration. It is not known whether this is because a high plasma LDL cholesterol concentration is necessary for the exertion of the effect represented by the $5 \mathrm{~A} / 6 \mathrm{~A}$ polymorphism or because LDL cholesterol concentration is correlated with some factors that modulate stromelysin expression via the $5 \mathrm{~A} / 6 \mathrm{~A}$ polymorphism or other mechanisms. The same biological mechanism may also explain why the $5 \mathrm{~A} / 6 \mathrm{~A}$ polymorphism was associated with change in luminal diameters only in the usual care group but not in the diet or diet plus cholestyramine treatment groups, because the mean in-trial plasma LDL cholesterol concentration in the UC group was higher than that in the D and DC groups. ${ }^{15}$

In this study, changes in diffuse ( $\triangle \mathrm{MAWS}$ ) and focal ( $\triangle$ MinAWS) coronary artery disease were estimated by serial angiography and this may not necessarily equate with changes in plaque growth, because other factors such as vascular tone will also contribute to measures of lumen diameter. However, comparison with animal studies suggests that this will at least partly reflect the genetic and environmental effects on the history of atherosclerosis. ${ }^{334}$ It has been shown that luminal size is a major determinant of the haemodynamic impact of coronary artery disease and is correlated with cardiac prognosis. ${ }^{35}$ Accordingly $\triangle \mathrm{MAWS}$ and $\triangle \mathrm{MinAWS}$ are significantly associated with changes in symptoms of angina. ${ }^{15}$ Compared with other methods for quantitating atheromatous plaque - such as sonographic imaging, ultrasound, and magnetic resonance imaging-serial coronary angiography has been regarded as the most powerful technique to estimate progression or regression of coronary atherosclerosis in vivo. Absolute measurement of the segmental width of a vessel by angiography is currently the only widely available method used to assess progression of diffuse and focal atherosclerosis. ${ }^{19}$

In summary, the $5 \mathrm{~A} / 6 \mathrm{~A}$ polymorphism in the stromelysin promoter seems to be associated with progression of coronary atherosclerosis in patients with mild baseline stenosis and particularly in those with a higher LDL cholesterol concentration. Although patients who receive only usual care would in general undergo more rapid progression of coronary artery disease, ${ }^{15}$ those who possess one or more $5 \mathrm{~A}$ alleles at this locus seemed to have a more favourable outcome. We emphasise that this is a small study and that these observations need to be confirmed in a larger sample of patients. It will be interesting also to see whether this polymorphism has any impact on risk of myocardial infarction. These results provide the first evidence of a common, potentially functional genetic variant in the promoter of a matrix metalloproteinase and suggest that there may be a link between this and the progression of coronary atherosclerosis. This supports the hypothesis that connective tissue remodelling, mediated by metalloproteinases, contributes to the pathogenesis of atherosclerosis.

We thank Professor Barry Lewis for continued help and encouragement, and acknowledge the contributions made by Dr D J Coltart and Dr L D R Smith (Cardiology) and Dr J N H Brunt (Medical Biophysics). This work was supported by grants from the British Heart Foundation (RG16 and PG92021), Unilever plc, the Chemical Pathology Fund of St Thomas' Hospital, and Bristol-Myers Ltd.

1 Davies MJ. A macro and micro view of coronary vascular insult in ischemic heart disease. Circulation 1990;82 (suppl II):II-38-II-46.

2 Fuster V, Stein B, Ambrose JA, Badimon L, Badimon JJ, Chesebro JH. Atherosclerotic plaque rupture and thrombosis. Evolving concepts. Circulation 1990;82 (suppl II):II-47-II-59.

3 Fuster V, Badimon L, Badimon J, Chesebro JH. The pathogenesis of coronary artery disease and the acute coronary syndrom

4 Ross R. The pathogenesis of atherosclerosis: an update. N Engl f Med 1986;314:488-500.

5 Richardson PD, Davies MJ, Born GVR. Influence of plaque configuration and stress distribution of fissuring of coronary atherosclerotic plaques. Lancet 1989;ii: 941-4.

6 Davies MJ, Bland MJ, Hangartner WR, Angelini A, Thomas AC. Factors influencing the presence or absence of acute coronary thrombi in sudden ischemic death. Eur Heart 7 1989;10:203-8.

7 Henney AM, Wakeley PR, Davies MJ, Foster K, Hembry R, Murphy G, Humphries S. Localization of stromelysin , Muression in atherosclerotic plaques by insin gene expression in atherosclerotic plaques by in situ

8 Muridization. Proc In: Royce PM, Steinman B. Connective tissue and its heritable disorders. New York, Wiley-Liss, 1993; heritable

9 Woessner JF Jr. Matrix metalloproteinases and their inhibitors in connective tissue remodeling. FASEB $f$ inhibitors in conne

10 Murphy G, Ward R, Gavrilovic J, Atkinson S. Physiological mechanism for metalloproteinase activation. Matrix 1992;suppl 1:224-30. 
11 Buttice G, Quinones S, Kurkinen M. The AP-1 site is required for basal expression but is not necessary for required for basal expression but is not necessary for Acids Res 1991;19:3723-31.

12 Diaz-Meco MT, Quinones S, Municio MM, Sanz L, Bernal D, Cabrero E, et al. Protein kinase C-independent expression of stromelysin by platelet-derived growth factor, ras oncogene, and phosphatidylcholinehydrolyzing phospholipase C. $\mathcal{F}$ Biol Chem 1991;266: 22597-602.

13 Case JP, Lafyatis R, Kumkumian GK, Remmers EF, Wider RL. IL-1 regulation of transin/stromelysin transcription in rheumatoid synovial fibroblasts appears to involve two antagonistic transcription pathways, an inhibitory, prostaglandin-dependent pathway mediated by cAMP, and a stimulatory, protein kinas

14 Frisch SM, Ruley HE. Transcription from the stromelysin promoter is induced by interleukin-1 and repressed by promoter is induced by interleukin-1 and repres

15 Watts GF, Lewis B, Brunt JNH, Lewis ES, Coltart DJ, Smith LDR, et al. Effects on coronary artery disease of lipid-lowering diet, or diet plus cholestyramine, in the St Thomas' atherosclerosis regression study (STARS). Lancet 1992;339:563-9.

16 Humphries SE, Lane A, Green FR, Cooper J, Miller GJ. Factor VII coagulant activity and antigen levels in healthy men are determined by interaction between factor VII genotype and plasma triglyceride concentration. Arterioscler Thromb 1994;14:193-8.

17 Miller SA, Dykes DD, Polesky HF. A simple salting out procedure for extracting DNA from human nucleated procedure for extracting Dis. Nucleic Acid Res 1988;16:1215.

18 Quinones S, Saus J, Otani Y, Harris ED, Kurkinen M. Transcriptional regulation of human stromelysin. $\mathcal{F}$ Biol Transcriptional regulation

19 Moncada S, Martin JF, Higgs A. Symposium on regression of atherosclerosis. Eur $f$ Clin Invest 1993;23: 385-98.

20 Ambrose JA, Winters SL, Arora RR, Eng A, Riccio A, Gorlin R, Fuster V. Angiographic evolution of coronary artery morphology in unstable angina. $\mathcal{F} \mathrm{Am}$ Coll Cardiol 1986;7:472-8.

21 Little WC, Constantinescu M, Applegate RJ, Kutcher MA, Burrows MT, Kahl FR, Santamore WP. Can coronary angiography predict the site of a subsequent myocardial infarction in patients with mild-to-moderate myocardial infarction in patients with mild-to-mode

22 Kerr LD, Holt JT, Matrisian LM. Growth factor regulate transin gene expression by c-fos-independent pathways. transin gene expression by

23 Mauviel A, Kahari VM, Kurkinen M, Evans CH, Uitto J. Leukoregulin, a T-cell derived cytokine, upregulates stromelysin-1 gene expression in human dermal fibroblasts: evidence for the role of AP- 1 in transcriptional activation. $f$ Cell Biochem 1992;50:53-61.

24 Machay AR, Ballin M, Pelina MD, Farina AR, Nason AM, Hartzler JL, Thorgeirsson UP. Effect of phorbol ester and cytokines on matrix metalloproteinase and tissue inhibitor of metalloproteinase expression in tumo and normal cell lines. Invasion Metastasis 1992;12: 168-84.

25 Buttice G, Kurkinen M. A polyomavirus enhancer A-binding protein-3 site and Ets-2 protein have a major role in the 12-O-tetradecanoylphorbol-13-acetate response of the human stromelysin gene. F Biol Chem 1993;268: 7196-204.

26 Kerr LD, Magun BE, Matrisian LM. The role of c-fos in growth factor regulation of stromelysin/transin gene growth factor regulation of stromelysin

27 Kerr LD, Miller DB, Matrisian LM. TGF- $\beta 1$ inhibition of transin/stromelysin gene expression is mediated through a transin/stromelysin gene expression is mediat

28 Nicholson RC, Mader S, Nagpal S, Leid M, RochetteEgly C, Chambon P. Negative regulation of the rat stromelysin gene promoter by retinoic acid is mediated by an AP1 binding site. EMBO $\mathcal{F} 1990 ; 9: 4443-54$

29 Sirum-Connolly $\mathrm{K}$, Brinckerhoff $\mathrm{CE}$. Interleukin-1 or phorbol induction of the stromelysin promoter requires an element that cooperates with AP-1. Nucleic Acids Res 1991;19:335-41.

30 Dawson SJ, Wiman B, Hamsten A, Green FR, Humphries $S E$, Henney AM. The two allele sequences of a common polymorphism in the promoter of the plasminogen polymorphism in the promoter of the plasminogen activator inhibitor-1 (PAI-1) gene respond differently to

31 Arntzenius AC. Regression of atherosclerosis. Benefit can be expected from low LDL-C and high HDL-C levels. be expected from low LDL-C and

32 Rouis M, Nigon F, Lafuma C, Hornebeck W, Chapman MJ. Expression of elastase activity by human monocytemacrophages is modulated by cellular cholesterol content, inflammatory mediators, and phorbol myristate acetate. Arteriosclerosis 1990;10:246-55.

33 Wissler RW, Vesselinovitch D. Studies of regression of advanced atherosclerosis in experimental animals and men. Ann N Y Acad Sci 1976;275:363-78.

34 La Ville AE, Seddon AM, Shaikh M, Rowles PM, Woolf $\mathrm{N}$, Lewis B. Primary prevention of atherosclerosis by lovastatin in a genetically hyperlipidaemic rabbit strain. Atherosclerosis 1989;78:205-10.

35 De Feyter PJ, Serruys PW, Davies MJ, Richardson P, Lubsen J, Oliver MF. Quantitative coronary angioLubsen J, Oliver MF. Quantitative coronary angionary atherosclerosis. Value, limitations, and implications for clinical trials. Circulation 1991;84:412-22. 